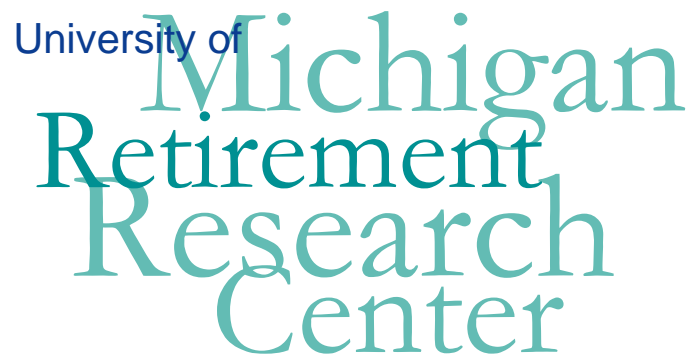

Working Paper WP 2007-165

Life-Cycle Models: Lifetime Earnings and the Timing of Retirement John Laitner and Dan Silverman

\begin{tabular}{|l|l|l|l|}
\hline $\mathrm{M}$ & $\mathrm{R}$ & Project \#: UM07-16 \\
\hline
\end{tabular} 


\title{
Life-Cycle Models: Lifetime Earnings and the Timing of Retirement
}

\author{
John Laitner \\ University of Michigan \\ Dan Silverman \\ University of Michigan
}

October 2007

Michigan Retirement Research Center

University of Michigan

P.O. Box 1248

Ann Arbor, MI 48104

http://www.mrrc.isr.umich.edu/

(734) 615-0422

\section{Acknowledgements}

This work was supported by a grant from the Social Security Administration through the Michigan Retirement Research Center (Grant \# 10-P-98362-5-04). The findings and conclusions expressed are solely those of the author and do not represent the views of the Social Security Administration, any agency of the Federal government, or the Michigan Retirement Research Center.

\section{Regents of the University of Michigan}

Julia Donovan Darrow, Ann Arbor; Laurence B. Deitch, Bingham Farms; Olivia P. Maynard, Goodrich; Rebecca McGowan, Ann Arbor; Andrea Fischer Newman, Ann Arbor; Andrew C. Richner, Grosse Pointe Park; S. Martin Taylor, Gross Pointe Farms; Katherine E. White, Ann Arbor; Mary Sue Coleman, ex officio 


\title{
Life-Cycle Models: Lifetime Earnings and the Timing of Retirement
}

\author{
John Laitner and Dan Silverman
}

\begin{abstract}
After dropping for a century, the average retirement age for U.S. males seems to have leveled off in recent decades. An important question is whether as future improvements in technology cause wages to rise, desired retirement ages will resume their downward trend, or not. This paper attempts to use HRS panel data to test how relatively high (or low) earnings affect male retirement ages. Our goal is to use cross-sectional earning differences to help anticipate likely time-series developments in coming decades. Our preliminary regression results show that higher earnings do lead to somewhat earlier retirement. Unless additional analysis changes the parameter estimates, the implication is that the downward trend in male retirement ages will ultimately return.
\end{abstract}

\section{Authors' Acknowledgements}

This paper is preliminary and should not be cited without permission of the authors. This work was supported by a grant from the Social Security Administration through the Michigan Retirement Research Center (Grant \# 10-P-98362-5). The opinions and conclusions are solely those of the authors and should not be considered as representing the opinions or policy of the Social Security Administration or any agency of the Federal Government. 


\section{Life-Cycle Models: Lifetime Earnings and the Timing of Retirement}

\section{Introduction}

After dropping for a century, the average retirement age for U.S. males seems to have leveled off in recent decades. An important question is whether as future improvements in technology cause wages to rise, desired retirement ages will resume their downward trend, or not. This paper attempts to use HRS panel data to test how relatively high (or low) earnings affect male retirement ages. Our goal is to use cross-sectional earning differences to help anticipate likely time-series developments in coming decades.

Our theoretical framework is the life-cycle model of household behavior. This paper builds from a general first-order restriction for optimal household retirement based on a so-called "free endpoint" condition from optimal control theory (e.g., Kamien and Schwartz [1981]). This condition may be adapted to a wide variety of life-cycle models and implies that, when choosing its best retirement age, a household balances its loss of current earnings, converted to units of utility, against its utility gain from retirement. The free endpoint condition generates our regression equations.

At this stage our tentative conclusion is that higher earnings may lead to earlier retirement. We believe that we have not yet exhausted the potential of our analysis, however, and that additional steps, which we outline below, may attenuate this connection.

The organization of this paper is as follows. Section 2 presents our theoretical framework, which is based on the life-cycle model of household behavior. Section 3 uses a firstorder condition for optimal retirement age to derive equations for estimation. Section 4 describes our data. Section 5 presents our estimation procedure and results. ${ }^{1}$ Section 6 concludes.

\section{Basic Framework}

We begin with a basic life-cycle framework. We derive our basic optimality condition for retirement and use it to construct a regression equation. The regression equation is the basis for this paper's empirical analysis.

For expositional convenience, begin with a single member household. The household chooses (i) how much to consume at each age and (ii) the age at which it will retire. Assume that work options are discrete: employers require full-time work; to obtain reduced work hours, an individual must retire altogether. The household starts at age and date 0, lives to age $T$, and, when not retired, has earnings flow $y_{t}$. The household solves

$$
\max _{c_{t}, R} \int_{0}^{R} e^{-\rho \cdot t} \cdot u\left(c_{t}, t, R\right) d t+\varphi\left(a_{R}, R\right)
$$

1 An earlier version of this paper, presented at the RRC Conference in Washington, 8/2007, employed linearizations and maximum likelihood estimation techniques. The present version eschews linearizations to obtain more precise results and turns to direct, nonlinear estimation of first-order conditions based on the method of moments. 


$$
\begin{gathered}
\text { subject to: } \dot{a}_{t}=r \cdot a_{t}+y_{t}-c_{t}, \\
a_{0}=0 .
\end{gathered}
$$

The function $\varphi\left(a_{R}, R\right)$ gives post-retirement utility conditional on retirement age $R$ :

$$
\begin{gathered}
\varphi(A, R) \equiv \max _{c_{t}} \int_{R}^{T} e^{-\rho \cdot t} \cdot u\left(c_{t}, t, R\right) d t \\
\text { subject to: } \dot{a}_{t}=r \cdot a_{t}-c_{t}, \\
a_{T} \geq 0, \\
a_{R}=A .
\end{gathered}
$$

Formulation I. Our basic formulation of the life-cycle model assumes intratemporal additivity of consumption expenditure and leisure. ${ }^{2}$ It assumes that for some $\gamma<1$ and $\Gamma>0$

$$
u(c, t, R) \equiv \begin{cases}\frac{1}{\gamma} \cdot[c]^{\gamma}, & \text { if } t<R \\ \frac{1}{\gamma} \cdot[c]^{\gamma}+\Gamma, & \text { if } t \geq R\end{cases}
$$

A household thus enjoys an improved utility function after retirement. Indeed, it is the prospect of this improvement that causes an agent to retire in the first place.

Analysis. Under Formulation I, this paper's attention focuses on the magnitude of $\gamma$. As we shall see, it is $\gamma$ that determines the likely correlation between the magnitude of earnings and optimal retirement age.

Maximizing in (1)-(2) with respect to consumption is a familiar problem. The solution is

$$
c_{t}=c_{o} \cdot e^{\nu \cdot t}
$$

where

$$
\nu \equiv \frac{r-\rho}{1-\gamma}, \quad c_{0}=\frac{Y(R)}{\int_{0}^{T} e^{-r \cdot s} \cdot e^{\nu \cdot s} d s}, \quad Y(R)=\int_{0}^{R} e^{-r \cdot s} \cdot y_{s} d s
$$

2 This formulation finds wide use in the existing literature - e.g., Bound et al. [1998], Rust and Phelan [1997], and Gustman and Steinmeier [1986, 2000]. 
Maximizing with respect to retirement age $R$ is a somewhat less common procedure. We can maximize with respect to $R$ taking (4) as given. This yields our so-called free endpoint condition (e.g., Kamien and Schwartz [1981], Laitner and Silverman [2005, 2007]):

$$
\frac{y_{R}}{\left[c_{R}\right]^{1-\gamma}}=\Gamma
$$

According to this condition, at the moment of its optimal retirement a household's loss of earnings, $y_{R}$, converted to units of utility through multiplication by the marginal utility of expenditure, $\left[c_{t}\right]^{\gamma-1}$, exactly counterbalances the gain in flow utility $\Gamma$ from retiring. If the left-hand side of (5) exceeds the right, the advantage of working longer overwhelms the advantage of immediate retirement; hence, if the left-hand side exceeds the right, the household should postpone its retirement beyond the age specified in (5).

Combining conditions (4)-(5), we have a basic equation: at optimal retirement age $R$, one has

$$
\ln \left(y_{R}\right)-(1-\gamma) \cdot \ln (Y(R))-(1-\gamma) \cdot\left[\nu \cdot R-\int_{0}^{T} e^{-r \cdot s} \cdot e^{\nu \cdot s} d s\right]=\ln (\Gamma)
$$

Suppose that earnings rise proportionately at every age for later cohorts. Changes in $y_{R}$ and $Y(R)$ cancel one another. However, if $\gamma \in(0,1)$, the second left-hand side term leads to ever greater retirement ages. If $\gamma<0$, the second term leads to ever earlier retirement ages. If $\gamma=0$, desired retirement age remains the same.

Formulation II. A second possible formulation has non-separable utility. We specify it as follows: for some $\gamma<1$ and $\lambda>1$, household flow utility satisfies ${ }^{3}$

$$
u(c, t, R) \equiv \begin{cases}\frac{1}{\gamma} \cdot[c]^{\gamma}, & \text { if } t<R \\ \frac{1}{\gamma} \cdot[\lambda \cdot c]^{\gamma}, & \text { if } t \geq R\end{cases}
$$

A household thus enjoys an improved utility function after retirement as every level of consumption generates a higher level of utility.

The analysis is only slightly different in the context of this paper - in particular, given this paper's data set (see below). In the denominator of the expression for $c_{0}$ above we need (see, for example, Laitner and Silverman [2005, 2007])

$$
\int_{0}^{R} e^{-r \cdot s} \cdot e^{\nu \cdot s} d s+\Lambda \cdot \int_{R}^{T} e^{-r \cdot s} \cdot e^{\nu \cdot s} d s, \quad \Lambda \equiv[\lambda]^{\frac{\gamma}{1-\gamma}} .
$$

The free endpoint condition is

3 This formulation also finds wide use in the literature - e.g., variants can be found in Auerbach and Kotlikoff [1987], Altig et al. [2001], French [2005], Laitner and Silverman [2005, 2007], Cooley and Prescott [1995]. See also Hurd and Rohwedder [2003], King et al. [1988], and Aguiar and Hurst [2005]. 


$$
\frac{y_{R}}{c_{R}}=1+\lambda^{\frac{\gamma}{1-\gamma}}+\frac{1}{\gamma} \cdot\left[\lambda^{\frac{\gamma}{1-\gamma}}-1\right]
$$

Inspection shows that this is observationally equivalent to (5) when $\gamma=0$ in the latter (leaving the only difference between the two models in the denominator of the expression for $\left.c_{0}\right)$.

In one empirically plausible case, average male retirement age does not change over time. Then Formulation I leads us to estimate $\gamma=0$. In respects beyond the scope of this paper - say, households' response to risk or to changing interest rates $-\gamma=0$ can be very restrictive. Formulation II, on the other hand, implies a constant average retirement age over time for any value $\gamma<1$, conceivably giving one latitude to pick values of $\gamma$ to fit other aspects of a larger data set.

Given this paper's primary goal, it henceforth utilizes Formulation I, which is simpler. If we estimate $\gamma=0$, then future work will turn to potentially richer, non-separable specifications.

Couples. Empirical prevalence leads us to focus on couples rather than single-adult households. We consider two cases. Our empirical work at this point, however, focuses on the first.

No Retirement Complementarity. In one specification, spouses vicariously benefit from each others utility but their household does not gain additional utility when both are retired together.

Returning to Formulation I, let the male's gain from retirement be $\Gamma^{m}$ and the female's $\Gamma^{f}$. To take into account the idea that two adults may be able to live more cheaply than two singles, let a couple correspond to $v_{t}$ "equivalent adults" (e.g., Tobin [1967]). Let $y^{f}\left(t, R^{f}\right)$ be the wife's earnings, which are 0 for $t \geq R^{f}$ (and, perhaps, at other ages). Similarly, let $y^{m}\left(t, R^{m}\right)$ be the husband's earnings at household age $t$. For concreteness, think of the household's age as the husband's age.

First, for a given $R^{f}$, think of the household as solving

$$
\begin{gathered}
\max _{c_{t}, R=R^{m}} \int_{0}^{R} e^{-\rho \cdot t} \cdot \frac{v_{t}}{2} \cdot\left[u\left(\frac{c_{t}}{v_{t}}, t, R\right)+u\left(\frac{c_{t}}{v_{t}}, t, R^{f}\right)\right] d t+\varphi\left(a_{R}, R\right) \\
\text { subject to: } \quad \dot{a}_{t}=r \cdot a_{t}+y^{m}(t, R)+y^{f}\left(t, R^{f}\right)-c_{t}, \\
a_{0}=0,
\end{gathered}
$$

where

$$
\begin{gathered}
\varphi(A, R) \equiv \max _{c_{t}} \int_{R}^{T} e^{-\rho \cdot t} \cdot \frac{v_{t}}{2} \cdot\left[u\left(\frac{c_{t}}{v_{t}}, t, R\right)+u\left(\frac{c_{t}}{v_{t}}, t, R^{f}\right)\right] d t \\
\text { subject to: } \quad \dot{a}_{t}=r \cdot a_{t}+y^{m}(t, R)+y^{f}\left(t, R^{f}\right)-c_{t}
\end{gathered}
$$




$$
\begin{aligned}
& a_{T} \geq 0, \\
& a_{R}=A .
\end{aligned}
$$

The solution has

$$
\begin{gathered}
c_{t}=\frac{e^{\nu \cdot t} \cdot v_{t} \cdot\left[Y^{m}\left(R^{m}\right)+Y^{f}\left(R^{f}\right)\right]}{\int_{0}^{T} v_{s} \cdot e^{-T \cdot s} \cdot e^{\nu \cdot s} d s}, \\
\frac{y_{R}^{m}}{\left[c_{R}\right]^{1-\gamma}}=\Gamma^{m} \quad \text { for } \quad R=R^{m} .
\end{gathered}
$$

Solving a symmetric problem (8)-(9) for $R=R^{f}$, condition (10) remains the same but

$$
\frac{y_{R}^{f}}{\left[c_{R}\right]^{1-\gamma}}=\Gamma^{f} \quad \text { for } \quad R=R^{f}
$$

replace (11).

Given (10), condition (11) implies a "reaction function" $R^{m}=R^{m}\left(R^{f}\right)$ showing the husband's optimal retirement age conditional on his retiring at age $R^{f}$. Condition (12) implies a second reaction function $R^{f}=R^{f}\left(R^{m}\right)$ for the wife.

Figure $1 \mathrm{~A}$ presents an example. ${ }^{4}$ If the reaction-function graphs cross at $\left(R^{m *}, R^{f *}\right)$, then we expect to see the husband retiring at age $R^{m}=R^{m *}$. Figure $1 \mathrm{~B}$ illustrates an outcome in which $R^{f *}=0$ and $R^{m *}>0$ at the optimal-choice point. In the latter case, the wife chooses never to engage in market work.

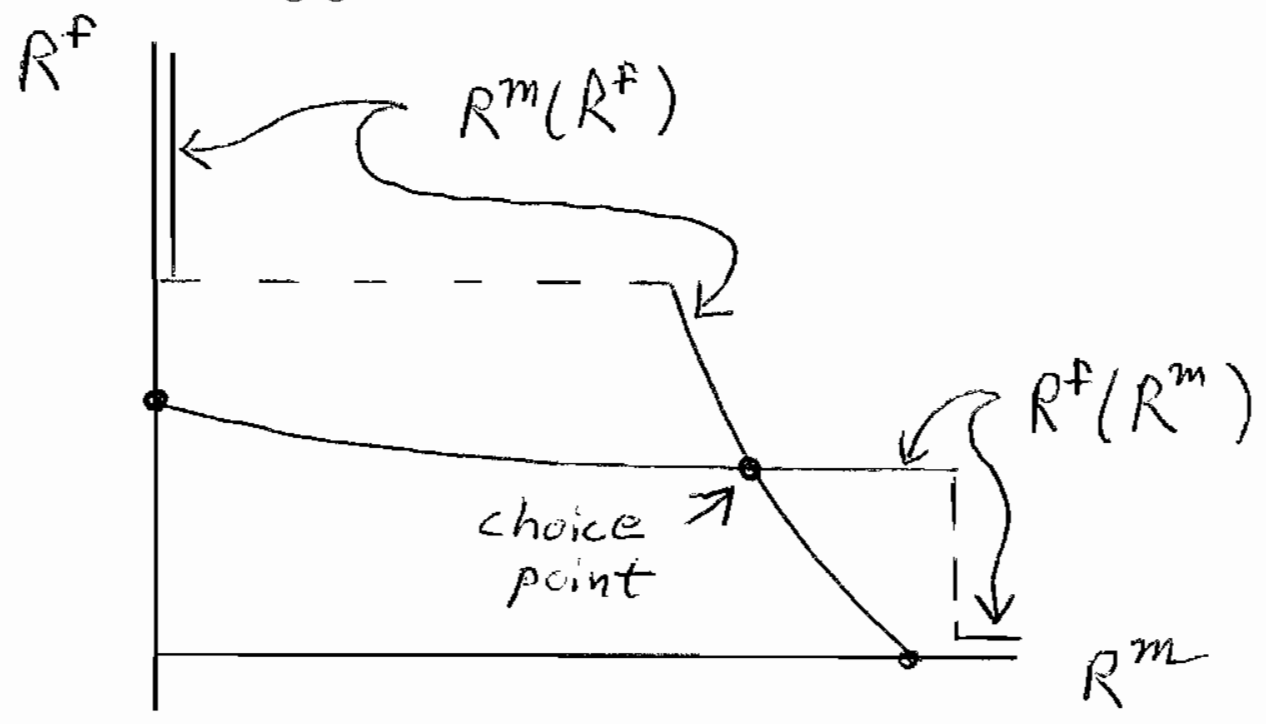

Figure 1A: Reaction functions $R^{m}\left(R^{f}\right)$ and $R^{f}\left(R^{m}\right)$

4 Low earnings in youth may lead a spouse either to never work, or to work a fairly substantial number of years - creating discontinuities in the reaction function graphs, as shown. 


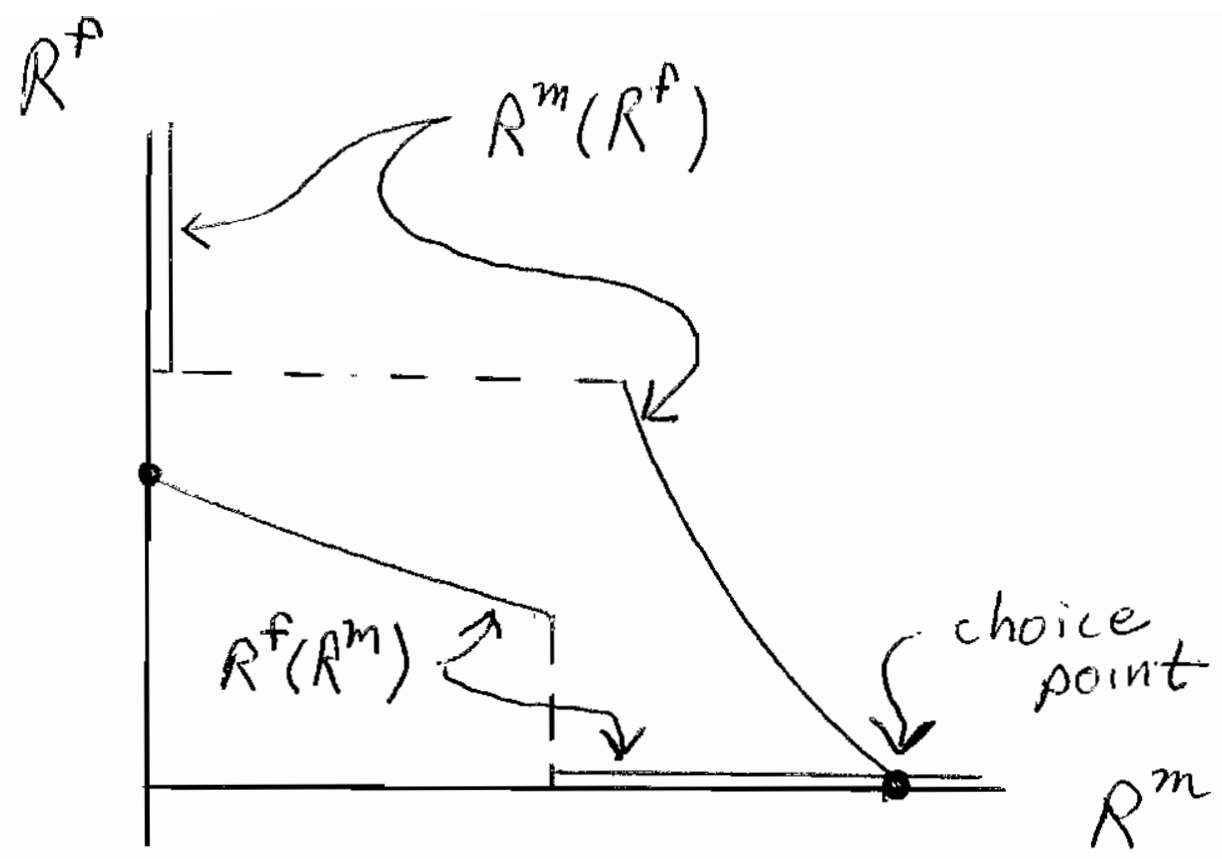

Figure 1B: Reaction functions with an intersection having $R^{f}=0$

Retirement Complementarity. It seems possible that a household can benefit most from retirement when both partners have stopped working. For example, a fully retired household might be free to move to an area with a favorable climate or nearby golf course. ${ }^{5}$ Our framework could incorporate this by including an addition to household utility, say, $\Gamma^{c}$, at the retirement of the second spouse. The consumption equation remains as above. The free endpoint conditions and reaction-function analysis, however, would become more elaborate.

This paper focuses on a specification without retirement complementarity; formulations with complementarity remain a topic for future research.

Children. As in Tobin [1967], we can extend the definition of $v_{t}$ to include additions when children are members of their parents' household - say, when children are ages $0-20 .^{6}$

\section{Empirical Analysis}

Combining (6) with (10)-(11), our basic equation for statistical analysis of $R=R^{m}$ is

$$
\begin{aligned}
& \ln \left(y_{R}^{m}\right)-(1-\gamma) \cdot\left[\ln \left(Y^{m}(R)+Y^{f}\left(R^{f}\right)\right)\right]- \\
& \quad(1-\gamma) \cdot\left[\nu \cdot R+\ln \left(v_{R}\right)-\ln \left(\int_{0}^{T} v_{s} \cdot e^{-\tau \cdot s} \cdot e^{\nu \cdot s} d s\right)\right]-\ln \left(\Gamma^{m}\right)=\tilde{\eta}
\end{aligned}
$$

${ }^{5}$ See, for example, Hamermesh [2005].

${ }^{6}$ See, for example, Laitner and Silverman [2005]. 
If all households have the same utility function, then differences in male age-earning profile shapes (which determine $y_{R}^{m}$ ), in male and female lifetime earnings, and in family composition profiles (which determine $v_{s}, 0 \leq s \leq T$ ) would determine interhousehold differences in $R=R^{m}$. We might set $\tilde{\eta}=0$, or we might assume that $\tilde{\eta}$ is a random variable (with mean 0) that reflects measurement error on the left-hand side of (13). Alternatively, we might assume that heterogeneity of preferences sets the right-hand side of (13) - in the sense that household $i$ derives pleasure $\Gamma^{m} \cdot e^{\eta_{i}}$ from male retirement, with $\eta_{i}$ an iid sampling from a random variable $\tilde{\eta}$ with mean 0 . In general, this paper adopts the latter assumption.

Our focus is $\gamma$. Accordingly, at this stage we calibrate $\nu=0.0273$ on the basis of Laitner and Silverman [2007]. ${ }^{7}$ And, we treat the left-hand side terms in (13) not varying with retirement age or earnings as a constant $\alpha$ :

$$
\alpha \equiv-\left[(1-\gamma) \cdot\left[\ln \left(v_{R}\right)-\ln \left(\int_{0}^{T} v_{s} \cdot e^{-r \cdot s} \cdot e^{\nu \cdot s} d s\right)\right]-\ln \left(\Gamma^{m}\right)\right] .
$$

In practice, of course, different households have different numbers of children and different timing of marriage and fertility. Although our data set has the virtue of measuring such factors, we leave their inclusion for future work. Our version of (13) is

$$
\ln \left(y_{R}^{m}\right)-(1-\gamma) \cdot\left[\ln \left(Y^{m}(R)+Y^{f}\left(R^{f}\right)\right)\right]-(1-\gamma) \cdot \nu \cdot R+\alpha=\tilde{\eta} .
$$

Although one could think of (14) as implicitly determining $R=R^{m}$ and then attempt to apply nonlinear least squares techniques, we estimate first-order condition (14) directly, using method of moments estimation. Thinking of the left-hand side of (14) as $q_{i}(\alpha, \gamma)$ and of the sample size as $I$, we estimate $(\alpha, \gamma)$ from a set of moment equations

$$
\frac{1}{I} \cdot \sum_{i=1}^{I} q_{i}(\alpha, \gamma) \cdot \vec{Z}_{i}=0
$$

where $\vec{Z}_{i}$ is a vector of instruments. Since we assume $E[\tilde{\eta}]=0$, the first component of $\vec{Z}_{i}$ can be 1 - in other words,

$$
\frac{1}{I} \cdot \sum_{i} q_{i}(\alpha, \gamma) \cdot 1=0
$$

To estimate two parameters, however, we need at least one more instrument. Choosing $\ln \left(y_{R}^{m}\right)$ or $Y^{m}(R)$ would be unsatisfactory because both depend on $R$, which (implicitly) is the endogenous variable in our equation. Our choice for a second instruement below is an index $e^{\mu_{i}}$ of the earning ability of the male in household $i$. Although we must estimate $\mu_{i}$, our data set has 20 or more observations of male earnings for most households. We use

$$
\vec{Z}_{i} \equiv\left(\begin{array}{c}
1 \\
E\left[\mu_{i}\right]
\end{array}\right) \quad \text { or } \quad \vec{Z}_{i} \equiv\left(\begin{array}{c}
1 \\
E\left[e^{\mu_{i}}\right]
\end{array}\right) .
$$

7 The latter estimate comes from Consumer Expenditure Survey data on consumption. 
Our second instrument is hardly unassailable. One might think, for instance, of each young household as having a vector of characteristics $\left(\eta_{i}, \mu_{i}, \eta_{i}^{f}, \mu_{i}^{f}, \kappa_{i}\right)$, where $\eta_{i}$ reflects male taste for leisure, $\mu_{i}$ male earning ability, $\eta_{i}^{f}$ female taste for leisure, $\mu_{i}^{f}$ female earning ability, and $\kappa_{i}$ taste for children (i.e., desired number of children). There is a distribution of this vector in the population. We can assume the expected value of the vector in the population is 0 with little sacrifice of generality since our earning dynamics equation and (14) include unrestricted constants. The second moments of the vector are a different matter, however. If $e\left[\eta_{i} \cdot \mu_{i}\right]=0$ (or $E\left[\eta_{i} \cdot e^{\mu_{i}}\right]=0$ ) this paper's second instrument is valid. Otherwise, it is not. Future work will investigate alternative instruments.

\section{Data}

The data set that we use is the Health and Retirement Study (HRS). ${ }^{8}$ In addition to demographic information, the HRS provides panel data on the retirement choices of older Americans. Further, it has lifetime earning records in the form of linked annual Social Security earning data for many of its men and women.

Male Retirement. The HRS asks men and women twice whether they are retired and what year they retired. We use the questions in sequence. If either says "retired," we set the individual's $R$ to the minimum of the listed year and the current year. We also check annual market-work hours in each survey wave.If a retired male subsequently works more than 1500 hours in a year, we drop his household from our sample - assuming that he retired but then changed his mind and returned to work. ${ }^{9}$

Male Earnings. The linked Social Security annual earning figures have the virtue of comprehensiveness - annual records go all the way back to 1951 - and of administrativerecord quality. Their disadvantages include right censoring at the Social Security earnings cap prior to 1981, and censoring at 100000, 250000, or 500000 thereafter (for reasons of confidentiality); lack of records for non-FICA jobs prior to 1981; and, lack of measurements of work hours. (After 1992, we have bi-annual HRS survey data, including both earnings and hours.) An additional potential problem, not peculiar to the HRS, is that earnings immediately prior to retirement might reflect shortened work hours or a period of disinvestment in human capital in anticipation of retirement.

We proceed as follows. We estimate an earnings dynamics equation for males:

$$
\ln \left(y_{i t}^{m}\right)=X_{i t} \cdot \beta+\mu_{i}+\epsilon_{i t},
$$

where $X_{i t}$ contains a quadratic in experience and time dummies (reflecting technological progress); the first error component, $\mu_{i}$, is a random individual effect; $\epsilon_{i t}$ is an annual, white-noise error that is independent of the individual effect; and, $\left(\mu_{i}, \epsilon_{i t}\right)$ is bivariate normal. We estimate (17) separately for high school and college graduates. We use maximum likelihood estimation (MLE). We know which observations are censored, and our estimation can take that into account as follows. Let

8 This paper uses HRS surveys from 1992-2002.

9 See, for example, Maestas [2004]. 


$$
e_{i t}=e_{i t}(\beta) \equiv \ln \left(y_{i t}^{m}-X_{i t} \cdot \beta\right) \text {, }
$$

let observations at times $s$ be uncensored, and let observations at times $t$ be censored. Then we solve

$$
\begin{gathered}
\min _{\beta}\{-\ln (\mathcal{L})\} \\
\ln (\mathcal{L}) \equiv \sum_{i} \ln \left(P_{i}\right) \\
P_{i} \equiv \int_{-\infty}^{\infty} p_{i}\left(\mu_{i}\right) d \mu_{i}, \\
p_{i}\left(\mu_{i}\right) \equiv\left[\prod_{s} \phi\left(e_{i s}-\mu_{i}, h_{\epsilon}\right)\right] \cdot\left[\prod_{t} \int_{e_{i t}-\mu_{i}}^{\infty} \phi\left(\xi, h_{\epsilon}\right) d \xi\right] \cdot \phi\left(\mu_{i}, h_{\mu}\right),
\end{gathered}
$$

where $i$ refers to households and $\phi(., h)$ to the normal density function with precision $h$. We want (18) to reflect full-time earnings, so we exclude observations with less than 4 quarters of Social Security earning credit for the year, with an earning amount less than 1500 annual hours times the minimum wage, or within two years of starting work or retiring. ${ }^{10}$ In a second approach, we additionally exclude observations (other than the first or last) adjoining a blank - the worry being that a male might, for example, have taken a non-FICA job and started or finished that job in the middle of a year - and males with less than 10 earning observations. Table A1 in the Appendix presents details on our sample size; Table A2 presents our earning-dynamics regression results.

Our next step predicts male earnings at every working age from (17). This has the advantage of overcoming censoring, imputing earnings from non-FICA jobs, and avoiding potential understatement of earning ability immediately prior to retirement (see the warning above). It has the potential disadvantage of overstating earnings during periods of unemployment or part-time work. Our measure of $Y^{m}\left(R^{m}\right)$ is the present value, with interest rate $r=0.04$, at age 50 of male earnings between the age of starting work and $R^{m}$.

In fact, by no means all males reach retirement in the survey data. We adapt our first-order condition to encompass this below. Furthermore, we write $Y^{m}(S)$ to mean the present value at age 50 of lifetime male earnings if the male reaches retirement in the survey, or earnings up to the maximum age the male attains in the survey data if the latter is short of his retirement age. Similarly for $y_{S}^{m}$ and $Y^{f}(S)$.

The correction for censoring seems to make a substantial difference (although our "tighter" samples, somewhat surprisingly, do not). In the high school educated sample, out of 11,620 observations, 3564 are censored and our imputations are higher in 2663 cases. $^{11}$ The average increase for the prediction for the 3564 censored figures is about 15

10 We assume a male with ED years of education starts work at age $=\min \{E D+6,18\}$.

11 Sampling variation means that not all of the predicted values are higher than the corresponding observation. 
percent. Average male lifetime earnings up to retirement - or the last age observable in the survey - in present value at age 50 , is $\$ 1,823,000$. (We use HRS household weights for all averages.) The tighter sample generates average total earnings of $\$ 1,820,000$. For collegeeducated males, there are 3039 censored observations among the 7709 total. Imputations are higher for 2722 cases. Comparing predictions to the original 3039 censored cases, we find almost a 39 percent increase. Average present value male earnings are $\$ 2,634,000$ for this group. For the tighter sample of college males, the predicted average present value of $Y^{m}(S)$ is $\$ 2,718,000$.

Women's Earnings. We do not filter female earnings below the minimum wage, with fewer than four Social Security quarters per year, or early or late in career. Thus, for the basic sample of high school educated males, we have 9551 spousal earnings observations - with positive female earnings for 408 households. For the college-male sample, we have 7152 spousal earning observations - with positive spousal earnings for 330 households. Censoring is much less prevalent: among spouses of high-school educated males, 272 observations are censored; among spouses of college-males, 333. In the former sample, the present value at age 50 (for the husband) of average spousal lifetime earnings is $\$ 305,000$; in the second sample, the average is $\$ 352,000$. These are substantial sums, but they are small relative to male totals. Evidently, women's earnings play a larger role for the households with high school educated males. We do not want to impute women's earnings for years with none reported, as many women in this generation did not work every year. In the end, we simply compute the present value (at husband's age 50) of lifetime female earnings using observed data points alone.

Distribution of Household Earnings. To estimate (14), we replace $\ln \left(y_{R}^{m}\right)$ with $E\left[\ln \left(y_{i S}^{m}\right)\right]$ where the role of $S$ is described above. We use our earnings dynamics equation (17), disregarding the short-term shocks $\epsilon_{i S}$. Then with the notation of (18),

$$
E\left[\ln \left(y_{i S}^{m}\right)\right]=X_{i S} \cdot \beta^{m}+E\left[\mu_{i}\right]=X_{i S} \cdot \beta^{m}+\frac{\int_{-\infty}^{\infty} \mu_{i} \cdot p_{i}\left(\mu_{i}\right) d \mu_{i}}{P_{i}} .
$$

We construct $\bar{Y}^{m}(S)$ from the present value at each age $t$ between starting work and $S$ of $X_{i t} \cdot \beta^{m}$. As always, compute the present value as of male age 50 . Then

$$
E\left[Y^{m}(S)\right]=\bar{Y}^{m}(S) \cdot E\left[e^{\mu_{i}}\right]=\bar{Y}^{m}(S) \cdot \frac{\int_{-\infty}^{\infty} e^{\mu_{i}} \cdot p_{i}\left(\mu_{i}\right) d \mu_{i}}{P_{i}} .
$$

Returning to (14), let $Y^{\text {post }}(S)$ be the present value at age 50 of male earnings after retirement. (If the male does not reach retirement in the survey, this is 0 . Otherwise, we take the earnings figures directly from the data, not using the earnings dynamics equation in this case.) Then

$$
\begin{aligned}
& E\left[\ln \left(Y^{m}(S)+Y^{\text {post }}(S)+Y^{f}(S)\right)\right]= \\
& \quad \frac{\int_{-\infty}^{\infty} \ln \left(\bar{Y}^{m}(S) \cdot e^{\mu_{i}}+Y^{\text {post }}(S)+Y^{f}(S)\right) \cdot p_{i}\left(\mu_{i}\right) d \mu_{i}}{P_{i}} .
\end{aligned}
$$


Finally, our second instrument comes from

$$
E\left[e^{\mu_{i}}\right]=\frac{\int_{-\infty}^{\infty} e^{\mu_{i}} \cdot p_{i}\left(\mu_{i}\right) d \mu_{i}}{P_{i}}
$$

Table A3 in the Appendix provides summary descriptions of key variables.

\section{Estimation}

We first describe the remainder of our estimation procedure. Then we present outcomes.

A complication in our estimation arises from the fact that not all males reach retirement within the sample time frame. In one instance, a man becomes disabled and leaves work at age prior to his optimal retirement age $R^{m}$ as computed in our model. ${ }^{12}$ In a second instance, a man dies before retiring. In a third, our last survey occurs before a man reaches retirement. We call these cases with $S<R^{m} .{ }^{13}$ In the notation of (14)-(15), when $S<R^{m}$ for household $i$, we assume that $q_{i}=q_{i}(\alpha, \gamma)$ provides an upper bound for $\eta_{i}$. In other words, we assume that the male has less desire to retire than the level which would have induced his retirement prior to disability, death, or the last survey. Assuming $\tilde{\eta}$ is $N\left(0, \sigma^{2}\right)$, for households with $S<R^{m}$ we have

$$
E\left[\eta_{i}\right]=\frac{\int_{-\infty}^{q_{i}} \eta \cdot \phi(\eta, h) d \eta}{\int_{-\infty}^{q_{i}} \phi(\eta, h) d \eta}
$$

where $\phi(., h)$ is the normal density function and $h$ is the precision, $h=1 / \sigma$.

To implement (23), we need to estimate $\sigma$. For households with $S<R^{m}$, we have

$$
E\left[\eta_{i} \cdot \eta_{i}\right]=\frac{\int_{-\infty}^{q_{i}} \eta^{2} \cdot \phi(\eta, h) d \eta}{\int_{-\infty}^{q_{i}} \phi(\eta, h) d \eta}
$$

Our complete estimation is then as follows. Define $S \equiv \min \left\{R^{m}\right.$, last sample age $\}$ and define

$$
\begin{aligned}
& q_{i}(\alpha, \gamma, \sigma) \equiv E\left[\ln \left(y_{S}^{m}\right)\right]-(1-\gamma) \cdot E\left[\ln \left(Y^{m}(S)+Y^{\text {post }}(S)+Y^{f}(S)\right)\right] \\
& \quad-(1-\gamma) \cdot \nu \cdot(S-50)+\alpha .
\end{aligned}
$$

We derive our estimate $(\widehat{\alpha}, \widehat{\gamma}, \widehat{\sigma})$ by finding $(\alpha, \gamma, \sigma)$ that satisfies three moment equations. Let

12 If a male classifies himself as "disabled," and if the year in which he became disabled preceded his retirement, we assume $S<R^{m}$.

13 A buyout offer could induce a similar phenomena, and future drafts will make use of HRS data on such offers - see, for example, Brown [2002]. 


$$
q_{i}^{*}(\alpha, \gamma, \sigma) \equiv \begin{cases}q_{i}(\alpha, \gamma, \sigma), & \text { if } S \geq R_{i}^{m} \\ E\left[\eta_{i}\right] \text { as in }(23), & \text { if } S<R_{i}^{m} .\end{cases}
$$

Then the first two moment equations are

$$
\frac{1}{I} \cdot \sum_{i} q_{i}^{*}(\alpha, \gamma, \sigma) \cdot \vec{Z}_{i}=0
$$

where $\vec{Z}_{i}$ is as in (16). Let

$$
q_{i}^{* *}(\alpha, \gamma, \sigma) \equiv \begin{cases}q_{i}(\alpha, \gamma, \sigma) \cdot q_{i}(\alpha, \gamma, \sigma), & \text { if } S \geq R_{i}^{m} \\ E\left[\eta_{i} \cdot \eta_{i}\right] \text { from }(24), & \text { if } S<R_{i}^{m} .\end{cases}
$$

Then the third moment equation is

$$
\frac{1}{I} \cdot \sum_{i}\left[q_{i}^{* *}(\alpha, \gamma, \sigma)-\sigma^{2}\right] \cdot 1=0
$$

Table 1 below presents results. For the standard and tight samples of households with both high school and college-graduate male heads, each $\widehat{\gamma}$ is less than 0 , though greater than -0.5. This is true for either set of instruments in (16). The T-statistics are large.

The estimates suggest that higher earnings induce somewhat earlier retirement. The implied effect is stronger in the samples of households headed by high school graduates.

This is preliminary work, however. Further steps will add a number of additional covariates. Several reasons to anticipate that final estimates of $\gamma$ might be even closer to 0 are: (i) correcting earnings for income taxes will tend to lower $y_{S}^{m}$ by a household's marginal tax rate and $Y^{m}(S)+Y^{\text {post }}(S)+Y^{f}(S)$ by its average tax rate - with the marginal rate quite possibly tending to be higher relative to the average rate for higher earners; and, (ii) higher earning households may tend to have fewer children - which will affect (13) if we stop simplifying through (14). As noted, we need to investigate alternatives to the second instrument in $\vec{Z}_{i}$ as well.

\section{Conclusion}

We have set up a nonstochastic life-cycle model of household behavior and derived a first-order condition for optimal retirement. Using HRS panel data on older married couples, including lifetime Social Security earning records for both men and women, we have derived method of moments estimates of several key parameters. With an additively separable utility function, we can estimate the additional utility flow accruing to males after retirement. More important, if we assume that utility is isoelastic in consumption, the sign of the corresponding exponent parameter predicts whether households with higher earnings will tend to retire earlier or later. Zero is the borderline case - implying an optimal retirement age independent of earning level. At this point, all of our results point toward an isoelastic parameter near zero but negative. A negative parameter implies 
Table 1. Estimated Coefficients for Equations (26)-(27): Health and Retirement Study Data 1992-2002 ${ }^{a}$

\begin{tabular}{|c|c|c|c|c|}
\hline \multirow{2}{*}{ Parameter } & \multicolumn{2}{|c|}{ High School Males } & \multicolumn{2}{|c|}{ College Males } \\
\hline & $\begin{array}{c}\text { Basic } \\
\text { Sample }\end{array}$ & $\begin{array}{c}\text { Tight } \\
\text { Sample }\end{array}$ & $\begin{array}{c}\text { Basic } \\
\text { Sample }\end{array}$ & $\begin{array}{c}\text { Tight } \\
\text { Sample }\end{array}$ \\
\hline \multicolumn{5}{|c|}{$\vec{Z}_{i}^{T}=\left(1, E\left[\mu_{i}\right]\right)$} \\
\hline $\begin{array}{c}\alpha \\
\text { (S.E.) } \\
\text { [T Stat.] }\end{array}$ & $\begin{array}{l}11.4824 \\
(1.2168) \\
{[9.4365]}\end{array}$ & $\begin{array}{l}10.8708 \\
(1.2526) \\
{[8.6785]}\end{array}$ & $\begin{array}{c}7.4765 \\
(0.6460) \\
{[11.5733]}\end{array}$ & $\begin{array}{c}7.9573 \\
(0.7232) \\
{[11.0023]}\end{array}$ \\
\hline $\begin{array}{c}\gamma \\
\text { (S.E.) } \\
\text { [T Stat.] }\end{array}$ & $\begin{array}{c}-0.4633 \\
(0.08208) \\
{[-5.6446]}\end{array}$ & $\begin{array}{c}-0.4225 \\
(0.08449) \\
{[-5.0008]}\end{array}$ & $\begin{array}{l}-0.2094 \\
(0.04260) \\
{[-4.9165]}\end{array}$ & $\begin{array}{c}-0.2406 \\
(0.04755) \\
{[-5.0603]}\end{array}$ \\
\hline $\begin{array}{c}\sigma \\
\text { (S.E.) } \\
\text { [T Stat.] }\end{array}$ & $\begin{array}{c}0.3196 \\
(0.02527) \\
{[12.6479]} \\
\end{array}$ & $\begin{array}{c}0.2975 \\
(0.02643) \\
{[11.2561]} \\
\end{array}$ & $\begin{array}{c}0.2718 \\
(0.01938) \\
{[14.0226]}\end{array}$ & $\begin{array}{c}0.2796 \\
(0.02114 \\
{[13.2260]} \\
\end{array}$ \\
\hline \multicolumn{5}{|c|}{$\vec{Z}_{i}^{T}=\left(1, E\left[e^{\mu_{i}}\right]\right)$} \\
\hline $\begin{array}{c}\alpha \\
\text { (S.E.) } \\
\text { [T Stat.] }\end{array}$ & $\begin{array}{l}11.2557 \\
(1.1452) \\
{[9.8286]}\end{array}$ & $\begin{array}{l}10.5679 \\
(1.1610) \\
{[9.1095]}\end{array}$ & $\begin{array}{c}6.7144 \\
(0.6138) \\
{[10.9389]}\end{array}$ & $\begin{array}{c}7.2246 \\
(0.6893) \\
{[10.4803]}\end{array}$ \\
\hline $\begin{array}{c}\gamma \\
\text { (S.E.) } \\
\text { [T Stat.] }\end{array}$ & $\begin{array}{c}-0.4480 \\
(0.07725) \\
{[-5.7995]}\end{array}$ & $\begin{array}{c}-0.4020 \\
(0.07825) \\
{[-5.1378]}\end{array}$ & $\begin{array}{l}-0.1589 \\
(0.04060) \\
{[-3.9147]}\end{array}$ & $\begin{array}{c}-0.1922 \\
(0.04546) \\
{[-4.2280]}\end{array}$ \\
\hline $\begin{array}{c}\sigma \\
\text { (S.E.) } \\
\text { [T Stat.] }\end{array}$ & $\begin{array}{c}0.3160 \\
(0.02408) \\
{[13.1223]}\end{array}$ & $\begin{array}{c}0.2927 \\
(0.02481) \\
{[11.7952]}\end{array}$ & $\begin{array}{c}0.2592 \\
(0.01665) \\
{[15.5650]}\end{array}$ & $\begin{array}{c}0.2680 \\
(0.01843) \\
{[14.5401]}\end{array}$ \\
\hline \multicolumn{5}{|c|}{ Sample Size } \\
\hline DFE & 406 & 377 & 328 & 289 \\
\hline
\end{tabular}

a. See text. 
higher earnings tend to lead to earlier optimal retirement age. There are, however, many interesting steps remaining for the future, and the text outlines how we anticipate that we will proceed. 


\section{References}

[1] Aguiar, Mark; and Hurst, Erik, "Consumption vs. Expenditure," Journal of Political Economy 113, no. 5 (October 2005): 919-948.

[2] Altig, David; Auerbach, Alan J.; Kotlikoff, Laurence J.; Smetters, Kent A.; Walliser, Jan, "Simulating Fundamental Tax Reform in the United States," American Economic Review 91, no. 3 (June 2001): 574-595.

[3] Auerbach, Alan J., and Kotlikoff, Laurence J., Dynamic Fiscal Policy. Cambridge: Cambridge University Press, 1987.

[4] Bound, John, Schoenbaum, Michael, Stinebrickner, Todd R., and, Waidmann, Timothy, 1998, "The Dynamic Effects of Health on the Labor Force Transitions of Older Workers." NBER Working Paper 6777, November 1998.

[5] Brown, Charles, "Early Retirement Windows," MRRC working paper WP 2002-028, October 2002.

[6] Cooley, Thomas, and Prescott, Edward, "Economic Growth and Business Cycles" in Thomas Cooley (ed.), Frontiers of Business Cycle Research. Princeton, J.J., Princeton University Press(1995): 1-38.

[7] French, Eric, 2005, "The Effects of Health, Wealth, and Wages on Labour Supply and Retirement Behavior." Review of Economic Studies (April 2005) 72: 395-427.

[8] Gustman, Alan L., and Steinmeier, Thomas L, "A Structural Retirement Model," Econometrica 54, no. 3 (May 1986): 555-586.

[9] Gustman, Alan L., and Steinmeier, Thomas L., "Retirement in dual career families: A Structural Model." Journal of Labor Economics 18(3) (July 2000): 503-545.

[10] Hamermesh, Daniel S., "Why Not Retire? The Time and Timing Costs of Market Work." Michigan Retirement Research Center Working Paper 2005-104, September 2005.

[11] Hurd, Michael; and, Rohwedder, Susann, "The Retirement-Consumption Puzzle: Anticipated and Actual Declines in Spending at Retirement," NBER working paper 9586 (2003).

[12] Kamien, Morton I., and Schwartz, Nancy L., Dynamic optimization : the calculus of variations and optimal control in economics and management. New York : North Holland, 1981.

[13] King, Robert; Plosser, Charles; and, Rebelo, Sergio, "Production, Growth and Business Cycles: I. The Basic Neoclassical Model," Journal of Monetary Economics 21, no. 2 (1988): 195-232.

[14] Laitner, John, and Silverman, Dan, "Estimating Life-Cycle Parameters from Consumption Behavior at Retirement." NBER working paper 11163, March 2005.

[15] Laitner, John, and Silverman, Dan, "Consumption and Retirement: Evaluating Social Security Reform with a Life-cycle Model." University of Michigan, mimeo, August 2007. 
[16] Maestas, Nicole, "Back to Work: Expectations and Realizations of Work After Retirement," MRRC working paper 2004-085, July 2004.

[17] Rust, John, and, Phelan, Christopher, "How Social Security and Medicare Affect Retirement Behavior in a World of Incomplete Markets," Econometrica 65, no. 4 (July 1997): 781-831.

[18] Tobin, James, "Life Cycle Saving and Balanced Growth," in W. Fellner (ed.), Ten Economic Studies in the Tradition of Irving Fisher. New York: Wiley, 1967. 


\section{Appendix}


Table A1. HRS Sample Size

\begin{tabular}{|c|c|c|}
\hline Criterion & Male ED Years 12 & Male ED Years 16-17 \\
\hline Household married only once & 2734 & 2734 \\
\hline Male meets ED criterion & 878 & 670 \\
\hline Spousal age difference $\leq 10$ & 848 & 649 \\
\hline Number kids $\leq 10$ & 846 & 649 \\
\hline Male birth year $1926-43$ & 831 & 634 \\
\hline Both spouses linked SSA records & 566 & 447 \\
\hline Adequate male retirement data & 565 & 447 \\
\hline Retired male never returns to work & 454 & 361 \\
\hline Woman does not work prior 1950 & 438 & 353 \\
\hline Male retirement age not $<52$ or $>71$ & 412 & 333 \\
\hline Households with male earnings & 411 & 330 \\
\hline Male earnings observations & 11620 & 7706 \\
\hline \multicolumn{3}{|c|}{ Tighter Sample (drop male earnings adjacent to blank; 10 or more figures per male) ${ }^{a}$} \\
\hline Households in sample & 380 & 294 \\
\hline Male earnings observations & 9978 & 6596 \\
\hline
\end{tabular}

a. See text. 
Table A2. HRS Earnings Regressions: Male ED Years 12

\begin{tabular}{|c|c|c|}
\hline Parameter & Regular Sample & Tighter Sample ${ }^{a}$ \\
\hline CONSTANT & $\begin{array}{c}9.1544 \\
(0.02954)\end{array}$ & $\begin{array}{c}9.1820 \\
(0.03014)\end{array}$ \\
\hline EXP & $\begin{array}{c}0.04553 \\
(0.004924)\end{array}$ & $\begin{array}{c}0.03423 \\
(0.004932)\end{array}$ \\
\hline $\mathrm{EXP}^{* * 2 / 100}$ & $\begin{array}{c}-0.06467 \\
(0.005255)\end{array}$ & $\begin{array}{c}-0.05482 \\
(0.005412)\end{array}$ \\
\hline DUMMY 1951-60 & $\begin{array}{c}0.000144 \\
(0.006187)\end{array}$ & $\begin{array}{c}0.005393 \\
(0.006365)\end{array}$ \\
\hline DUMMY 1961-65 & $\begin{array}{c}0.03892 \\
(0.006408)\end{array}$ & $\begin{array}{c}0.04545 \\
(0.006591)\end{array}$ \\
\hline DUMMY 1966-70 & $\begin{array}{c}0.05017 \\
(0.006672) \\
\end{array}$ & $\begin{array}{c}0.06410 \\
(0.006921)\end{array}$ \\
\hline DUMMY 1971-75 & $\begin{array}{c}-0.009391 \\
(0.006235)\end{array}$ & $\begin{array}{c}0.000102 \\
(0.006313)\end{array}$ \\
\hline DUMMY 1976-80 & $\begin{array}{c}-0.03517 \\
(0.005755)\end{array}$ & $\begin{array}{c}-0.02713 \\
(0.005636)\end{array}$ \\
\hline DUMMY 1981-85 & $\begin{array}{l}-0.005861 \\
(0.005481)\end{array}$ & $\begin{array}{c}0.002436 \\
(0.005364)\end{array}$ \\
\hline DUMMY 1986-90 & $\begin{array}{c}-0.02082 \\
(0.005654)\end{array}$ & $\begin{array}{c}-0.01667 \\
(0.005489)\end{array}$ \\
\hline DUMMY 1991-95 & $\begin{array}{c}0.008214 \\
(0.007107)\end{array}$ & $\begin{array}{c}0.005728 \\
(0.006829)\end{array}$ \\
\hline DUMMY 1996+ & $\begin{array}{c}0.03297 \\
(0.01009)\end{array}$ & $\begin{array}{c}0.03953 \\
(0.009567)\end{array}$ \\
\hline PRECISION $h_{\epsilon}$ & $\begin{array}{c}2.7978 \\
(0.02306)\end{array}$ & $\begin{array}{c}2.9907 \\
(0.02606)\end{array}$ \\
\hline PRECISION $h_{\mu}$ & $\begin{array}{c}2.8770 \\
(0.1077) \\
\end{array}$ & $\begin{array}{c}3.1106 \\
(0.1202) \\
\end{array}$ \\
\hline \multicolumn{3}{|c|}{ Summary Statistics } \\
\hline$\overline{\mathrm{DFE}}$ & 11606 & 9964 \\
\hline$-\ln ($ Likelihood $)$ & 5,576 & 4,376 \\
\hline
\end{tabular}

a. See text and Table 1. 
Table A2. HRS Earnings Regressions (cont.): Male ED Years 16-17

\begin{tabular}{|c|c|c|}
\hline Parameter & Regular Sample & Tighter Sample ${ }^{a}$ \\
\hline CONSTANT & $\begin{array}{c}9.4959 \\
(0.06844)\end{array}$ & $\begin{array}{c}9.5520 \\
(0.07560)\end{array}$ \\
\hline EXP & $\begin{array}{c}0.0371 \\
(0.008198)\end{array}$ & $\begin{array}{c}0.03800 \\
(0.008801)\end{array}$ \\
\hline $\mathrm{EXP}^{* *} 2 / 100$ & $\begin{array}{c}-0.05846 \\
(0.009326)\end{array}$ & $\begin{array}{c}-0.05472 \\
(0.009729)\end{array}$ \\
\hline DUMMY 1951-60 & $\begin{array}{c}0.01122 \\
(0.01586)\end{array}$ & $\begin{array}{c}-0.006491 \\
(0.01796)\end{array}$ \\
\hline DUMMY 1961-65 & $\begin{array}{c}0.06665 \\
(0.01229)\end{array}$ & $\begin{array}{c}0.06867 \\
(0.01370)\end{array}$ \\
\hline DUMMY 1966-70 & $\begin{array}{c}0.07328 \\
(0.01243)\end{array}$ & $\begin{array}{c}0.07550 \\
(0.01382)\end{array}$ \\
\hline DUMMY 1971-75 & $\begin{array}{c}-0.003701 \\
(0.01100)\end{array}$ & $\begin{array}{c}-0.000185 \\
(0.01191)\end{array}$ \\
\hline DUMMY 1976-80 & $\begin{array}{c}0.05524 \\
(0.009030)\end{array}$ & $\begin{array}{c}-0.05733 \\
(0.009515)\end{array}$ \\
\hline DUMMY 1981-85 & $\begin{array}{c}0.01592 \\
(0.008025)\end{array}$ & $\begin{array}{c}0.01786 \\
(0.008531)\end{array}$ \\
\hline DUMMY 1986-90 & $\begin{array}{c}0.004728 \\
(0.008093)\end{array}$ & $\begin{array}{c}0.000344 \\
(0.008546)\end{array}$ \\
\hline DUMMY 1991-95 & $\begin{array}{c}0.02648 \\
(0.009430)\end{array}$ & $\begin{array}{c}0.01825 \\
(0.009733)\end{array}$ \\
\hline DUMMY 1996+ & $\begin{array}{c}0.01445 \\
(0.01195)\end{array}$ & $\begin{array}{c}0.01156 \\
(0.01204)\end{array}$ \\
\hline PRECISION $h_{\epsilon}$ & $\begin{array}{c}2.6634 \\
(0.02895)\end{array}$ & $\begin{array}{c}2.7875 \\
(0.03202)\end{array}$ \\
\hline PRECISION $h_{\mu}$ & $\begin{array}{c}1.9494 \\
(0.07996) \\
\end{array}$ & $\begin{array}{c}1.9495 \\
(0.08442) \\
\end{array}$ \\
\hline \multicolumn{3}{|c|}{ Summary Statistics } \\
\hline$\overline{\mathrm{DFE}}$ & 7692 & 6582 \\
\hline$-\ln ($ Likelihood $)$ & 3,461 & 2,851 \\
\hline
\end{tabular}

a. See text and Table 1. 
Table A3. Sample Characteristics ${ }^{a}$

\begin{tabular}{|c|c|c|c|c|}
\hline Statistic & $E[\mu]$ & $E\left[e^{\mu}\right]$ & $E\left[Y^{m}(S)\right]$ & $Y^{f}(S)$ \\
\hline \multicolumn{5}{|c|}{ High School Male } \\
\hline \multicolumn{5}{|c|}{} \\
\hline Minimum & -1.0258 & 0.36 & 519,000 & 0 \\
\hline Lower Quartile & -0.2492 & 0.77 & $1,116,000$ & 125,000 \\
\hline Median & -0.03420 & 0.97 & $1,392,000$ & 261,000 \\
\hline Upper Quartile & 0.2179 & 1.25 & $1,791,000$ & 429,000 \\
\hline Maximum & 1.4194 & 4.16 & $5,570,000$ & $1,413,000$ \\
\hline Mean & -0.02069 & 1.04 & $1,473,000$ & 302,000 \\
\hline \multicolumn{5}{|c|}{ College Male } \\
\hline Minimum & -1.3174 & 0.27 & 546,000 & 0 \\
\hline Lower Quartile & -0.3896 & 0.68 & $1,315,000$ & 147,000 \\
\hline Median & -0.03911 & 0.97 & $1,821,000$ & 290,000 \\
\hline Upper Quartile & 0.1969 & 1.22 & $2,349,000$ & 473,000 \\
\hline Maximum & 1.8011 & 6.12 & $11,658,000$ & $1,414,000$ \\
\hline Mean & -0.04365 & 1.11 & $2,157,000$ & 353,000 \\
\hline
\end{tabular}

a. See text. Basic samples only. 
Table A3. Sample Characteristics (cont.) ${ }^{a}$

\begin{tabular}{|c|c|c|c|c|}
\hline Statistic & $Y^{\text {post }}(S)$ & $\begin{array}{c}E\left[\ln \left(Y^{m}(S)\right.\right. \\
+Y^{\text {post }}(S) \\
\left.\left.+Y^{f}(S)\right)\right]\end{array}$ & $E\left[\ln \left(y_{S}^{m}\right)\right]$ & $E\left[y_{S}^{m}\right]$ \\
\hline \multicolumn{5}{|c|}{ High School Male } \\
\hline Minimum & 0 & 13.51 & 9.06 & 9000 \\
\hline Lower Quartile & 0 & 14.14 & 9.87 & 19,000 \\
\hline Median & 0 & 14.36 & 10.11 & 25,000 \\
\hline Upper Quartile & 7000 & 14.55 & 10.34 & $\begin{array}{l}31,000 \\
\end{array}$ \\
\hline Maximum & 160,000 & 15.59 & 11.49 & 99,000 \\
\hline Mean & 7000 & 14.35 & 10.11 & 26,000 \\
\hline \multicolumn{5}{|c|}{ College Male } \\
\hline Minimum & 0 & 13.40 & 9.49 & 13,000 \\
\hline Lower Quartile & 0 & 14.34 & 10.39 & 33,000 \\
\hline Median & 0 & 14.63 & 10.70 & 45,000 \\
\hline Upper Quartile & 30,000 & 14.85 & 10.96 & 58,000 \\
\hline Maximum & $1,739,000$ & 16.27 & 12.54 & 283,000 \\
\hline Mean & 32,000 & 14.63 & 10.72 & 52,000 \\
\hline
\end{tabular}

a. See text. Basic samples only. 